\title{
Habitar y medir el territorio.Los vínculos con la tierra de colonos, ocupantes y guaraníes en Misiones
}

Inhabiting and measuring the territory. Links with the land of colonists, peasants and Guaranis in Misiones

\section{Gabriela Schiavoni}

\section{OpenEdition}

\section{Journals}

\section{Electronic version}

URL: http://journals.openedition.org/corpusarchivos/2317

DOI: $10.4000 /$ corpusarchivos. 2317

ISSN: $1853-8037$

\section{Publisher}

Diego Escolar

\section{Electronic reference}

Gabriela Schiavoni, « Habitar y medir el territorio.Los vínculos con la tierra de colonos, ocupantes y guaraníes en Misiones », Corpus [En línea], Vol. 8, No 1 | 2018, Publicado el 14 noviembre 2018, consultado el 20 abril 2019. URL : http://journals.openedition.org/corpusarchivos/2317 ; DOI : $10.4000 /$ corpusarchivos.2317

This text was automatically generated on 20 April 2019. 


\section{Habitar y medir el territorio.Los vínculos con la tierra de colonos, ocupantes y guaraníes en Misiones}

Inhabiting and measuring the territory. Links with the land of colonists, peasants and Guaranis in Misiones

Gabriela Schiavoni

\section{EDITOR'S NOTE}

Fecha de recepción del original: 19/03/2018

Fecha de aceptación para publicación: 28/05/2018

Este artículo analiza las interacciones con respecto a la tierra de grupos guaraníes, colonos y ocupantes agrícolas en la provincia de Misiones (nordeste de Argentina). A fines del siglo XIX, las extensiones públicas y privadas son mensuradas con el fin de llevar a cabo planes de colonización. Los grupos indígenas y los agricultores que no acceden al poblamiento planificado desarrollan modos alternativos de apropiación del ambiente, que caracterizamos aquí en base a las actividades productivas. Nuestro argumento subraya la existencia de una conexión estrecha entre el control estatal y la medida de superficies continuas destinadas a la agricultura comercial. En este contexto, la territorialidad guaraní resulta difícilmente encuadrable en el accionar oficial. Ofrecemos una descripción que permite situar históricamente los vínculos y los saberes relativos al espacio, a partir de la distinción entre la perspectiva de habitar y la medida geométrica como forma abstracta de control del espacio.

\section{Introducción}

1 La nueva prórroga de la ley de emergencia de tierras indígenas en la Argentina ${ }^{1}$ señala la relevancia de la problemática $\mathrm{y}$, al mismo tiempo, las dificultades que experimenta el 
Estado para producir un espacio uniforme. La comprensión del tema en la provincia de Misiones deja entrever el entramado de vínculos que mantienen con la tierra distintos actores: colonos, ocupantes e indígenas.

Nuestro trabajo describe esta trama, atendiendo especialmente al enmarcado estatal de la territorialidad guaraní, retomando fuentes periodísticas e informaciones obtenidas durante el trabajo de campo, realizado principalmente entre ocupantes agrícolas de la fracción más recientemente poblada del territorio provincial (deptos. Guaraní, San Pedro y Gral. Belgrano), en contacto con poblaciones indígenas.

El espacio de la territorialidad estatal implica que la tierra es pensada antes que habitada; se basa en un patrón geométrico de reparto efectuado "sobre una (supuesta) tabula rasa" (Garavaglia 2011, p. 36). La medición de la tierra se desarrolló en conexión con su uso agrícola, y hasta la introducción del sistema métrico (fines del siglo XVIII y comienzos del XIX), los métodos de estimación de superficies fueron el trabajo y la siembra (Kula 1999).

4 En el caso de Misiones, la medición geométrica del suelo data solo de finales del siglo XIX y está asociada a la colonización del recién creado territorio nacional (Schiavoni 2016). Los agrimensores instituyeron la superficie, delimitando las parcelas mediante el trazado de líneas rectas.

5 El poblamiento planificado se desarrolló hasta mediados del siglo XX, estabilizando una estructura agraria basada en el predominio de pequeñas y medianas explotaciones familiares, en coexistencia con latifundios. A su vez, en forma paralela a la colonización, se desplegó la ocupación agrícola no planificada de las tierras fiscales despobladas, configurando una tendencia de larga duración en Misiones, aceptada a posteriori por el Estado. A diferencia del colono, el ocupante del frente pionero contribuye a la formación de los diversos lugares que habita y su trayectoria biográfica es al mismo tiempo geográfica. A mediados del siglo XX, cuando concluye el reparto de la tierra pública, las últimas extensiones vacantes (situadas en la fracción nordeste del territorio) quedaron libradas a las dinámicas familiares de la instalación espontánea (Schiavoni 1995). Más tarde, este poblamiento avanzará sobre propiedades que las empresas madereras abandonan una vez concluida la extracción del monte nativo. El censo de ocupantes de tierras privadas (Baranger y Schiavoni, 2005) registra este proceso, cuya regularización quedará encuadrada por la ley de arraigo y colonización, sancionada en el año 2004.

6 En contraste con la colonización empresarial, en la ocupación no planificada, la tierra no existe como superficie previamente objetivada sino que se constituye como tal en forma simultánea al poblamiento. Así, se "cortan chacras" y se "marcan rumbos" en base a la experiencia directa del espacio y a un saber derivado del habitar, instrumentalizado al servicio de la mercantilización informal de parcelas. El tamaño de los predios se ajusta a la superficie explotable por una familia, ubicándose en torno a la extensión del lote fiscal agrícola de 25 ha. Los relatos de los ocupantes subrayan el carácter "al margen" del modo de obtención de los predios: "es clandestino, compramos fiado: cada uno marcó su chacra y sacó el rumbo"; "compramos de un hombre que gustaba de cortar chacra"; "compramos la mejora y el hombre que nos vendió no había visto ningún papel".

7 No obstante, la figura de "la mejora", en tanto elemento que organiza la apropiación, representa el ejercicio de unos derechos emanados del trabajo agrícola, convertido en una magnitud susceptible de establecer equivalencias y fundamentar reclamos. El objetivo de apropiación individual derivado del trabajo sobre la tierra diferencia la territorialidad móvil de los ocupantes de aquella practicada por los mbya guaraní en la provincia. ${ }^{2}$ 
8 En efecto, la territorialidad indígena no implica la propiedad privada de la tierra. Los dominios de las comunidades son habitados por conjuntos de grupos domésticos emparentados, bajo la dirección de un cacique que asigna las fracciones de tierra para el uso de cada familia. La existencia de estos agrupamientos no depende de una localización fija, ya que frecuentemente se desplazan o se subdividen siguiendo redes parentales.

Los conflictos por la tierra guaraní en la provincia se desatan a partir de la reforma constitucional de 1994. En esa década también se intensifica la lucha por la tierra de los ocupantes agrícolas. En Misiones, a diferencia de lo que ocurre en otras regiones de Argentina, campesinos e indígenas no constituyen un mismo actor, de modo que en varios litigios aparecen enfrentados, aunque tengan en común la experiencia directa de habitar el espacio.

La sedentarización informal de la ocupación agrícola no planificada (ocupantes) y la territorialidad móvil de los grupos guaraníes (Schiavoni y Gallero 2017) existen a contrapelo del reparto geométrico. Los vínculos fluidos que mantienen con la tierra, característicos del habitar, se despliegan en un espacio conocido mediante prácticas de recorrido, compuesto de manchas y senderos formados por el uso (trillos). En efecto, para el que habita: "el mundo no tiene superficie propiamente hablando. En su andar cruza distintos tipos de superficie (...) gracias al modo en que reaccionan estas superficies (...) percibe el mundo (...) son superficies que están en el mundo y no superficies del mundo" (Ingold 2013, p.107).

11 En las páginas que siguen describiremos las formas de territorialidad que se desarrollaron históricamente en la provincia de Misiones, deteniéndonos en el modo en que coexisten la superficie cuadriculada, mensurable cuantitativamente, y las tramas de entrelazamientos impulsados por personas, objetivables cualitativamente mediante recorridos. ${ }^{3} \mathrm{La}$ agricultura sedentaria desempeñó un rol central en los procesos de individuación del espacio estatal, subordinando las territorialidades vinculadas a la explotación de recursos silvestres.

12 Advirtiendo acerca del sesgo genealógico contenido en la noción de territorio indígena del convenio de la OIT de 1989, Ingold (2000) subraya que la oposición entre los que son de la tierra y los que están sobre la tierra organiza la diferencia entre pueblos indígenas y colonos en la conciencia pública de Occidente:

Los colonos han roto sus lazos con la naturaleza y se han expandido poblando distintos territorios del globo. Y puesto que la historia se eleva por encima del suelo de la naturaleza, es concebida frecuentemente como colonización. La tierra es algo para ser ocupado, pero en sí misma no contribuye a la constitución de los que la ocupan (Ingold 2000, p. 135).

14 Separada de la naturaleza y convertida en escenario de la historia, la tierra deviene algo abstracto. Para los que la habitan, en cambio, la tierra es en sí misma la historia: tiene una textura definida por lugares que intervienen en la constitución del grupo. Los vínculos del habitar se sostienen en fricción contraria con la producción del espacio estatal, sin ser patrimonio exclusivo de las poblaciones originarias, ya que caracterizan también los procesos de la ocupación no planificada de los pequeños agricultores no indígenas. En efecto: "el uso de categorías fijas puede ocultar las relaciones complejas que los agricultores de los frentes pioneros mantienen con su ambiente" (Eloy y Emperaire 2011). 
la Inglaterra de los inicios de la modernidad "el hábito de plantar en línea recta cereales y legumbres no solo era una manera eficaz de usar un espacio limitado sino también un modo agradable de imponer el orden humano sobre un mundo natural desordenado" (Thomas 1985, p. 334). Los paisajes salvajes serán valorizados recién a fines del siglo XVIII, como una reacción al cuadriculado del campo inglés impuesto por los cercamientos. numerosas dificultades para compatibilizar la cuadrícula del diseño en damero con la presencia de pobladores y mejoras. Uno de ellos anota: “Dado el gran número de [pobladores] y su ubicación caprichosa, (...) no era posible realizar un trazado regular pues las líneas debían quebrarse continuamente para salvar poblaciones y mejoras" (Duplicado de Mensura № 112, 1926).

23 Es decir, en contraste con los colonos, y a semejanza de los indígenas, los agricultores del frente pionero (ocupantes) participan de la constitución de los lugares a medida que los habitan. A su vez, el hecho de que la apropiación esté mediada por el trabajo agrícola sobre una parcela introduce una variante con respecto a la posesión indígena, cuya inscripción en el espacio genera marcas menos evidentes. 

agrícola, ya sea como jornadas de trabajo con arado o como cantidad de granos de siembra (Kula 1999). A fines del siglo XVIII, en la región central de Francia "la seterée de tierra es la única medida conocida (...) circunscribe el terreno que puede ser cultivado con un setier" [medida de capacidad para granos, que oscila entre 150-300 litros] (Kula 1999, p. 39). Asimismo, "el arpent no se mide en varas o pies (...) sino en jornadas, es decir en campos que pueden ser arados por un hombre en el transcurso de un día" (Kula 1999, p. 38). una medida puramente convencional, independiente de los cuerpos y los recipientes locales, cuyo carácter científico la torna universal. La producción de un espacio codificado por parte del Estado es solidaria de este tipo de cálculo.

30

Varios litigios recientes en torno a las tierras indígenas en la provincia de Misiones tienen su origen en este aspecto. Así, por ejemplo, un cementerio guaraní resultó arrasado dado el carácter cotidiano de las señales de posesión (un zapato, una vasija, una madera tallada; El Territorio 20/7/2008). En otro caso, la frecuentación de un antiguo rozado, fuente de aprovisionamiento de frutales y de plantas medicinales para la comunidad indígena, no fue tenida en cuenta como índice de ocupación.

estándares y constituyó la vara que organizó la distribución de parcelas en Misiones a lo largo de todo el siglo XX.

conocimiento del espacio del movimiento concreto. Son figuras abstractas orientadas a permitir el cálculo y el control a distancia. La elaboración de Ingold (2013) en torno a la transformación de las líneas proporciona una herramienta para situar históricamente los vínculos y saberes relativos al territorio. ${ }^{6}$ La cuestión del enmarcado estatal de la territorialidad indígena puede analizarse como la metamorfosis en superficies sobre la tierra de los senderos y rastros en la tierra. precisión. En su estudio sobre los horticultores amateurs en Francia, Florence Weber (2002) destaca la exactitud de las respuestas relativas al tamaño del terreno frente a la variabilidad de las estimaciones vinculadas al tamaño de la huerta. En efecto, en el primer caso se trata de un dato que ha pasado por numerosos intermediarios (catastro, título de propiedad, contrato de alquiler) y se expresa en hectáreas o en metros cuadrados. El cálculo del tamaño de la huerta, en cambio, responde a las percepciones corporales del que la trabaja (esfuerzo con la azada, estimación a ojo, etc.) y la medida es fluctuante.

\section{Del movimiento corporal a la razón abstracta: kilos, litros y jornadas de tierra}

Cuando a fines del siglo XIX, el agrimensor Queirel (Duplicado de Mensura № 12, 1891, Dirección de Catastro de la provincia de Misiones) visita el territorio de Misiones con el fin de medir una propiedad, señala la vigencia de la medida de siembra como forma de estimación de la tierra, con su equivalencia en metros cuadrados y jornadas de trabajo. Así, escribe: 
31 En Misiones la unidad de medida actual es el alquer, medida portuguesa que se emplea para contar una gran cantidad de sembrado. Para sembrar cereales, maíz, poroto etc. significa decir un alquer de rozado (aunque la medida sea de capacidad), la extensión que ocupaban los granos contenidos en esa capacidad, que equivale a 40 litros, y sembrado cuatro [granos] por pie o planta y a distancia un grupo de otro de $1,87 \mathrm{~m}$. A esto llaman los correntinos, paraguayos y brasileros que se ocupan de ello, el alquer que contiene una superficie de $24.200 \mathrm{~m} 2$. También dicho por los brasileros, un rectángulo de 50 brazas de frente por 100 de fondo (cada braza tiene 2,20 m). En monte virgen, un solo hombre emplea promedio 20 días de trabajo por alquer ${ }^{7}$ (Duplicado de Mensura № 12, 1891). También a fines del siglo XIX, describiendo la agricultura de la región, Bourgoing (1896) manifiesta su sorpresa frente al hecho de que el censo de 1886 del Paraguay compute la producción agrícola en líneos, en lugar de hacerlo en superficie ${ }^{8}$. Trabajo y tierra, dos de las pseudomercancías identificadas por Polanyi (2007) establecen sus magnitudes mutuamente, en conexión con la actividad agrícola. En efecto, así como el trabajo mide la tierra, la tierra mide el trabajo.

De este modo, la tarefa [tarea], es una medida de superficie utilizada para organizar el trabajo en las plantaciones de caña de azúcar del nordeste brasilero. ${ }^{9}$ Se establece midiendo cuadros que parten de las brazas, estimación que conserva la conexión con el cuerpo humano (cada braza corresponde a 10 palmas de una mano, aproximadamente a 2,2 metros). Con la ayuda de una vara de esa longitud se determinan cuadros (cuadrados de 22 metros de lado), y con seis de esos cuadros se forma una línea (132 m. por $22 \mathrm{~m}$., es decir $3025 \mathrm{~m} 2$, o un tercio de hectárea) que constituye la tarefa, un trabajo a ser realizado en tiempo variable. ${ }^{10}$

En la década de 1930, un morador bien dispuesto podía hacer dos tarefas por semana (Sigaud 1979). Con la implantación de la legislación laboral en Brasil (1963), la jornada de trabajo corresponderá a la tarefa menor o conta, un área cuadrada de diez metros de lado (100 m2). ${ }^{11}$ En Misiones, la tarefa no tiene un correlato en superficie: es la unidad de contratación de un trabajo que debe hacerse en forma perentoria y requiere una cuota diaria mínima (la cosecha de yerba mate, por ejemplo).

La vigencia de medidas no convencionales de la tierra señala las dificultades que experimenta el Estado en la codificación del espacio. Es un indicador de la incorporación marginal a la sociedad nacional de determinadas áreas y segmentos sociales. Así, los kilombolas de Tocantins utilizan actualmente la tarefa bahiana ${ }^{12}$ para estimar sus rozados (Vizolli y Mendes 2016).

37 También los estudios sobre procesos de ocupación de la frontera agraria brasilera (Musumeci 1988; Araujo 1993) documentan el uso del sistema de líneas (y no de hectáreas) en la estimación de las parcelas. En estos casos, el trabajo agrícola es la única fuente disponible de cálculo del tamaño de los predios; el sistema de líneas, además, resulta útil para establecer con anticipación los términos de la participación asociada sobre un mismo rozado.

38 En Misiones, durante la realización del censo de ocupantes de tierras privadas (Baranger y Schiavoni 2005), en los inicios del siglo XXI, se observó el uso de medidas locales de origen brasileño, tales como el celemín ( $25 \mathrm{~m}$ por $12,5 \mathrm{~m}$ ), el alquer (110 m por $220 \mathrm{~m}$, o sea 24.000 m2) y el cuadro (área cuadrada, inferior a media hectárea).

De este modo, coexisten en los Estados modernos formas alternativas de codificación del espacio. La tierra medida en esfuerzo laboral, o en estimaciones que mantienen una 
conexión con el cuerpo humano, considera la experiencia directa como base para calcular la extensión, haciendo del trabajo agrícola un indicador del espacio habitado y un medio para reclamar derechos de propiedad.

En el caso de las comunidades guaraníes, la acción de habitar no segmenta el espacio diferenciando superficies. Los vínculos con la tierra no están escindidos de la naturaleza, demandando traducciones que conecten las prácticas de uso con los formatos codificados de la estimación estatal.

Los saberes de recorrido puestos en juego delimitan áreas derivadas de desplazamientos en busca de hierbas medicinales, alimentos, materiales para cestería, etc. Así, en el marco de un litigio por la tierra en la provincia, las comunidades mbya ubicadas en una reserva natural reclamaron su derecho al espacio que transitan, poniendo de manifiesto la familiaridad con el ambiente a través de un mapa, en el que registraron los senderos formados por el uso, la identificación de cursos de agua y de recursos vegetales y animales.

\subsection{Plantar y medir: las semillas de la territorialidad estatal}

Las extensiones domesticadas por la agricultura sedentaria, al separar la tierra de la naturaleza, contribuyen a establecer superficies que intervienen en la producción de un espacio abstracto por parte del Estado. A fines del siglo XIX, los comisionados de agricultura, enviados por el gobierno nacional al recién creado territorio de Misiones con el fin de sentar las bases del poblamiento, identifican como un problema el carácter silvestre y dependiente del monte que exhiben los usos productivos del suelo allí vigentes.

Con respecto a la recolección de yerba mate, observan que:

una de las causas que (...) dificultarían (...) hacer de la elaboración de la yerba una verdadera industria, consiste en que las plantas de yerba existentes en la selva no se encuentran reunidas en grandes agrupaciones, sino en pequeñas manchas diseminadas, a veces a largas distancias unas de otras e interceptadas por serranías y arroyos (...) sin contar (...) con el inconveniente del bosque dentro del cual se encuentran (Yssouribehere 1904, p. 86).

Incluso, la domesticación incipiente de la yerba, con miras a transformarla en un cultivo de renta para los pequeños agricultores, requiere inicialmente la proximidad del monte, tal como advierte el naturalista viajero, comisionado por el Estado nacional:

los colonos actuales (...) especialmente los que se radicaran en las cercanías del bosque o de yerbales antiguos, tendrán la facilidad de trasplantar los arbolitos nuevos a sus chacras (...). En una hectárea un colono puede colocar mil árboles de yerba cómodamente, es decir, que de su yerbal (...) podría sacar cada 3 años por valor de 400 pesos oro (Burmeister 1899, p. 34).

El trasplante de mudas silvestres provenientes del monte constituía el modo vigente de multiplicación de yerba mate a fines del siglo XIX, tal como describe Ambrosetti en su recorrido por las quintas de la zona de San Ignacio, en las que "no faltan las frutas silvestres así como también varias plantaciones de yerba mate hechas con plantitas huachas, que han sido trasplantadas, y que bien cuidadas se han desarrollado alcanzando ya la talla de arbustos" (Ambrosetti 2008, pp. 98-99).

También los yerbales de los jesuitas, que iniciaron el cultivo en el siglo XVIII con el fin de independizarse de los montes de Maracayu y contrarrestar la explotación de los 
encomenderos españoles (Meliá 2006; Furlong 1978), se formaron a partir de plántulas provenientes de manchones silvestres cercanos. Solo a mediados del XVIII, la multiplicación se llevará a cabo mediante semillas germinadas en almácigos, y aun así, las plantaciones no constituirán superficies homogéneas, ya que el cultivo mantuvo un carácter hortense, con cuidados intensivos para cada arbusto (Furlong 1978) y el cultivo intercalado de maíz, mandioca y leguminosas. Cuando Azara visita la región, en 1784, evalúa los yerbales de las reducciones y de los pueblos de indios, tomando en consideración el número de plantas, y no la superficie, como unidad de cuenta. ${ }^{13}$ Rengger (2010), médico y naturalista suizo que recorre el Paraguay en las primeras décadas del siglo XIX, observa el diseño en hilera de los yerbales formados a partir de semillas. Relata que:

en las cercanías de las poblaciones guaraníticas (...) se disponen plantaciones ordenadas de caá (...) la semilla se coloca en lo profundo (...) Las plantas jóvenes son transplantadas en hileras y en torno a cada árbol se tiende un foso para recoger el agua de lluvia (Rengger 2010, p. 350).

Con anterioridad al control estatal del espacio, la territorialidad de la explotación de yerba mate silvestre, actividad realizada en el siglo XIX por empresas que contrataban población nativa, estaba compuesta por manchones identificables en el monte solo mediante los saberes de recorrido detentados por el descubiertero:

individuos encargados de explorar el monte en busca de yerba (...) Como la yerba busca con preferencia la costa de los arroyos y nunca los cerros, es sobre los primeros que se lleva a cabo la exploración. Encontrada una 'pinta' se recorre el curso superior e inferior de la corriente de agua, sobre una orilla primero y sobre la otra después, calculándose el rendimiento del manchón por la superficie aproximada que ocupe y la densidad en que se encuentra el árbol buscado. Los descubierteros son tan prácticos que rara vez incurren en una exageración en sus cálculos (Yssouribehere 1904, p. 95).

48 En esas manchas, "cada tarifero (cortador, minero ${ }^{14}$ ) tiene de antemano señalada, con mayor o menor precisión, la zona en que debe operar y los árboles diversos del manchón suelen estar marcados con anterioridad para evitar su aprovechamiento por otro que no sea su descubridor" (Yssouribehere1904, pp. 87-88). Niklison (2009), un inspector de trabajo que recorre yerbales y obrajes de explotación de monte nativo en 1914, estima la labor del tarefero en número de árboles (cada obrero corta de 6 a 8 árboles por día).

Es decir, el espacio de la recolección silvestre no se evalúa en superficie sino en cantidad de árboles. ${ }^{15}$ Aun así, el Reglamento de yerbales de 1876, que fija las condiciones de explotación y fiscalización de "los yerbales de San Javier, Santa Ana, Corpus y los del otro lado del Campo Grande", regula el tamaño de la concesión en superficie, estableciendo un área de 6 cuadras cuadradas por cortador (equivalente a 9,6 ha ${ }^{16}$ ), especificando que el campamento total no podrá exceder las 60 cuadras cuadradas (es decir, 96 ha). También Bourgoing (1894), cuando describe la organización del trabajo en los yerbales, a finales del XIX, alude a la producción de un espacio basado en líneas y superficies. Así, afirma que:

Señálanles los capataces de Caatí (yerbal) la parte en que han de trabajar mediante piques o pequeñas galerías abiertas de antemano con ese objeto, y que sirven además, de límite a cada uno de los trabajadores facilitando de este modo un trabajo ordenado (...) Cada minero al ir a tomar posesión del retazo que le ha sido señalado, va provisto de un hacha, un machete y un raído (Bourgoing 1894, pp. 238-239, el resaltado es mío).

51 La superficie emergerá gradualmente mediante la inscripción de líneas, constituidas por las hileras de mudas de yerba trasplantadas desde el monte, que irán introduciendo un 
orden rectilíneo en el territorio de manchas de la explotación silvestre. La multiplicación de yerba mate a partir de semillas, que se generaliza en las primeras décadas del siglo XX, independizará los yerbales cultivados de sus parientes silvestres, convirtiendo la extensión en hectáreas, en el modo estándar de estimación.

Aun así, las primeras plantaciones modernas se establecen en estrecha conexión con los espacios silvestres; el comisionado nacional de agricultura observa que:

en San Ignacio se va a iniciar el cultivo de la yerba mate en gran escala (...) El representante y director de esta empresa (...) ha comprado unas cuantas chacras que ocupaban antiguos pobladores (...) La yerba mate estaba abandonada entre el monte y las capoeras altas (... ) Varias de esas chacras (...) han sido limpiadas a machete, poniéndose al descubierto no menos de quince mil plantas de yerba mate (Yssouribehere 1904, p. 82). ${ }^{17}$

La asociación de las grandes plantaciones de yerba con los ejemplares del monte se evidencia también en el relato que ofrece Niklison, en 1914, acerca de la formación de los yerbales de San Ignacio: "Dos grandes empresas, Martin y Cía., y La Plantadora, han acometido con el mayor entusiasmo (...) la importante obra de repoblar de yerbales a Misiones (...). Las plantaciones se han hecho por mudas - plantas pequeñas traídas de manchones cercanos- o por ejemplares de viveros, pues la yerba se reproduce perfectamente de semilla (Niklison 2009, pp. 38-39).

54 Los colonos alemanes que arriban a Misiones en las primeras décadas del siglo XX procedentes de Brasil refieren el inicio del cultivo de yerba en conexión con el monte y en base a saberes derivados del habitar. En uno de esos relatos, leemos:

Con sus andanzas por los montes, Jacobo Bischoff un día encuentra en algunos lugares plantas de yerba mate, grandes árboles con mucho follaje y semillas. Los Bischoff conocían esas plantas de Brasil, donde la elaboraban para su consumo (....). Cuando comenta su hallazgo a la familia, deciden cosechar esas plantas y juntar semillas para sembrar almácigos y criar plantines, para luego plantarlos en la chacra (Bischoff 2004, p. 66).

La multiplicación de yerba mate a través de semillas se convertirá en el modo privilegiado de control del territorio por parte del Estado, demandando la autonomización del yerbal domesticado con respecto a los manchones silvestres. El especialista del gobierno nacional recomienda:

Hay que trabajar hasta poder ofrecer a los colonos un método definitivo, fácil, eficaz y rápido de germinación para que posean (...) en el menor tiempo, el mayor número de plantas (...). Allí donde hay algún manchón de yerba o plantas diseminadas en el monte vecino (...) la reproducción no es tan difícil, porque entonces es muy posible formar un plantel trayendo mudas (...) Cuando ese manchón o plantas diseminadas (...) no se encuentra próximo (...) la dificultad de conseguir la formación de yerbal se hace casi insuperable, porque el colono no puede perder tiempo en recorrer grandes distancias o en hacer exploraciones entre el monte en una zona demasiado lejana a su residencia (Yssouribehere 1904, pp. 84-85).

56 A partir de 1926, las obligaciones especiales para las colonias agrícolas de Misiones incluirán el requisito de cultivar con yerba mate el $25 \%$ de la superficie del lote fiscal normal, convirtiéndose en el cultivo ancla de las explotaciones familiares (Bartolomé 1990). ${ }^{18}$

La medición geométrica de superficies homogéneas destinadas a la agricultura sedentaria y apropiables individualmente constituyó el instrumento de control estatal del territorio 
de Misiones a lo largo del siglo XX, solo desafiado en las últimas décadas por la mediación ambiental.

De este modo, quedaron al margen las formas de individuación del espacio que no escinden la tierra de la naturaleza, constituidas por recorridos que entretejen los ambientes del monte, la capuera ${ }^{19} \mathrm{y}$ el rozado.

\section{Una horticultura en connivencia con lo silvestre: el espacio liso de la naturaleza} de 1970, Descola (1988) señala la preferencia por el término horticultura, antes que agricultura, "con el fin de caracterizar explícitamente el aspecto individual que el tratamiento de la planta cultivada puede tener respecto a las técnicas agrícolas de los países templados cerealicultores" (Descola 1988, p. 299). una consecuencia del sistema de coivara ${ }^{20}$ y la consociación de diversas plantas. A mediados del siglo XIX, Rengger (2010) describe una de estas rozas en el Alto Paraná paraguayo como "un lugar (...) sembrado sin orden con mandioca, zapallos, calabazas, caña de azúcar, maíz y bananas" (Rengger 2010, p.125). poniendo de manifiesto el carácter reversible del proceso de domesticación. La naturaleza complementaria de esta coexistencia, fue subrayada por Strathern (2014) a propósito de las sociedades melanesias, señalando que se trata de distintas esferas de influencia: una basada en relaciones de control y cría, y otra, menos ordenada, localizada fuera de esos límites, pero con la que también se entablan interacciones y negociaciones (Strathern 2014 , p. 54). Los vínculos fluidos entre los ambientes silvestres y cultivados contribuyen a la producción del espacio tramado.

63 La instauración de una división neta entre los ámbitos silvestres y cultivados resultó problemática en las misiones jesuíticas guaraníes, minando las bases de la agricultura sedentaria y la cría de animales (Sarreal 2013).

64 En el guaraní colonial que registra Montoya (1639), la chacra (cog) cuando ya no tiene uso agrícola es denominada cocuera y continúa siendo una fuente de recursos. Refiere la existencia de unos porotos denominados cocueriba, porque se dan bien en las chacras abandonadas Montoya (1639, p. 98).

65 Asimismo, la reutilización de los rozados asilvestrados favorece el advenimiento de cultígenos latentes (Keller 2012), haciendo que los antiguos barbechos o capueras mantengan su relevancia como lugares de reproducción de plantas espontáneas. Esta interacción entre los ejemplares cultivados y sus parientes silvestres es fuente de diversidad (Rival 2001).

Los vínculos sociales con la tierra forman el espacio habitado, ya que los lugares se crean a través de los recorridos. Así, el "derecho de capuera" le permite a los ocupantes fiscales de la frontera agraria de Marañón (Brasil) reclamar el dominio sobre el espacio 
asilvestrado de su rozado anterior, instituyendo la familiarización con la tierra como fuente de propiedad (Musumeci 1988, p. 83).

En el caso de las comunidades guaraníes, los grupos y los lugares son aspectos mutuamente relacionados de un mismo proceso. El uso de la tierra es inseparable de los lazos de cacicazgo y parentesco, que se ejercen más allá de una localización fija.

En los inicios del territorio nacional de Misiones, la medición geométrica del suelo y el desarrollo de la agricultura comercial, proveyeron el marco del control estatal. Las memorias elaboradas por los enviados del Ministerio de Agricultura en esta etapa no incluyen referencias a la agricultura indígena; el "agricultor montaraz" que registran corresponde a nativos de origen brasileño, que utilizan el saracuá o palo puntiagudo, "un resabio indígena", que deberá ser reemplazado por la azada y el arado. Constatan la fuerte dependencia de la agricultura nativa con respecto a la selva, de modo que: "Condenar a un hombre de esos a abandonar el rozado e instalarse fuera del monte, sería condenarlo a la muerte; moriría de nostalgia: la nostalgia de la selva!" (Yssouribehere 1904, p. 99).

69 A principios del siglo XX, el padre Müller (1989) describe la agricultura guaraní del Alto Paraná paraguayo señalando que "en su estado actual es lastimosa, siendo que las plantaciones son ridículamente pequeñas en extensión que ofrecen apenas subsistencia para algunos meses" (Müller 1989, p. 40). Reconoce la presencia del palo de sembrar o yvirá racuá, agregando que la introducción de la azada es reciente y que la limpieza infrecuente-, de las plantaciones es efectuada con machete. Aun así, el componente vegetal de la alimentación que enumera pone en evidencia una apreciable variedad de cultígenos de maíz, mandioca, batata. ${ }^{21}$

70 Para esa misma época, el naturalista Bertoni (1928) subrayaba la superioridad del saber agrícola guaraní sobre el maíz, "especialmente las técnicas empleadas para mantener la pureza de las clases, la selección de semillas y variedades" (Bertoni 1927, p. 120).

71 Cuando el botánico Martínez Crovetto (1968) estudia la agricultura indígena de Misiones en la década de 1960, considera que "los sistemas de cultivo y gran parte de las plantas y variedades que utilizan son el legado de un antiguo patrimonio cultural, que se ha venido manteniendo con muy escasas variaciones a través del tiempo" (Martínez Crovetto 1968, p. 1). Destaca como característica notable la práctica de consociación de cultivos y la mezcla irregular que se observa en los rozados, ocasionada por plantas del monte que han quedado y por la resiembra natural de algunos anuales, que se prefiere dejarlos para un aprovechamiento posterior.

Más recientemente Pochettino (2007) describe la actividad agrícola de los mbya guaraní de la zona central de Misiones, registrando que los espacios de cultivo (kokué) oscilan entre media y una hectárea, son irregulares y de límites difusos. La cosecha no constituye un momento definido del ciclo agrícola, ya que los tubérculos quedan en la tierra y se recolectan a medida que se consumen. La multiplicación de las plantas es gestionada de manera autónoma, mediante la conservación de semillas y esquejes. Las especies fundamentales de la alimentación (maíz, mandioca y batata) exhiben una variedad intraespecífica apreciable. El patrimonio de especies propias es distinguido de las foráneas ("de los colonos"), entre las que incluyen el maíz colorado y la mandioca negra, producidos con destino a la venta. La oposición entre el maíz blando, como elemento de cultura tradicional, y el maíz duro, como factor de aculturación, es menos nítida en Misiones que la observada en grupos guaraníes de Brasil (Souza 1987; Felipim 2001). ${ }^{22}$ 
73 En relación con la importancia que reviste la agricultura en las estrategias de las familias guaraníes, Pochettino (2007) señala que solo tres de las 31 chacras estudiadas tuvieron un funcionamiento regular en las campañas consideradas en el marco de la investigación (1996-2004), ya que el asalariamiento en la cosecha de yerba mate interfiere en la producción agrícola. Constata que algunos pobladores (cinco) "manifiestan una especial inclinación hacia la horticultura y tienen una segunda chacra en zonas relativamente distantes (hasta $1 \mathrm{~km}$ ) de la vivienda" (Pochettino 2007, p. 39). Y agrega que los responsables de estas chacras estables "no solo practican regularmente la horticultura sino que también demuestran saberes especiales en plantas medicinales y una particular dedicación a la recolección" (Pochettino 2007, p. 42). Es decir, la mayor inclinación a la actividad agrícola no sustituye sino que complementa la frecuentación de los espacios silvestres con fines de recolección.

Concebido como una trama de senderos impulsados por las personas, los animales y las plantas, el espacio habitado comprende el monte, los bordes de los arroyos y la capuera, además de los rozados y las viviendas (Crivos et al. 2007). Solo los curadores especializados utilizan el monte como fuente de obtención de plantas medicinales, mientras que los legos recolectan medicinas en las capueras y en las chacras (Crivos et al. 2007).

Un estudio realizado sobre otra comunidad mbya de la zona centro-oeste de la provincia (Keller 2007), localizada en un predio de 57 ha constata el uso de cuatro ambientes: la selva alta, el borde de arroyo, el borde de selva y el barbecho. Y, si bien, el borde del arroyo constituye el ambiente con mayor biodiversidad (138 especies), es el monte o selva alta el que detenta el mayor porcentaje de especies útiles (93 especies). Los usos son principalmente medicinales, en segundo lugar para la provisión de leña y en tercer término para alimentos. Las utilizaciones restantes están vinculadas a la confección de artesanías para la venta y utensilios domésticos. ${ }^{23}$

Las prácticas de recolección y la frecuentación del monte también forman parte de las estrategias de reproducción de los pequeños agricultores de la provincia. Así, entre los pequeños productores de la zona oriental de Misiones, próxima a la reserva de biosfera Yabotí, más de la mitad de las plantas medicinales utilizadas (93 especies) corresponde a ejemplares silvestres recolectados en el monte y en la vegetación secundaria (Keller y Romero 2006).

El estudio de Kujawska y Pieroni (2015) sobre el uso de plantas medicinales y alimenticias entre agricultores de origen polaco en el Alto Paraná misionero (Wanda y Gdor. Lanusse, depto. Iguazú) muestra que, aun cuando la fuente principal de obtención sean las áreas cultivadas, hay un $36 \%$ de plantas utilizadas (15 especies) que corresponde a plantas nativas silvestres recolectadas en áreas de vegetación secundaria y de barbecho.

El privilegio acordado a la mediación del trabajo agrícola en la producción del espacio estatal ejerce sus efectos sobre el reparto de tierras en Misiones, confiriéndole protagonismo a la figura del colono y desprestigiando las formas silvestres de individuación del ambiente. Esto se evidencia en las declaraciones oficiales de finales de la década de 1980, cuando está en juego la distribución del último remanente de tierra fiscal. Así, los funcionarios expresan: "Habrá tierra para hijos de colonos" (El Territorio 18/08/1988), y también: "La Provincia protege y ayuda al verdadero colono, al que aprovecha la tierra, no al que la deja en capuera" (El Territorio 05/02/1989). 
79 Los pequeños productores en busca de tierras libres utilizan la condición silvestre como indicio de disponibilidad. Este ha sido el origen de varios litigios que involucran tanto a propiedades forestales abandonadas como a reservas indígenas. Los campesinos ocupantes justifican la apropiación argumentando la ausencia de una agricultura sedentaria. En el caso de una reserva indígena, localizada en plena frontera agraria provincial (fracción nordeste) uno de los ocupantes relata: "Había capuerón cuando los colonos entramos"; “[cuando llegamos] Era capuera abandonado, chircales. ${ }^{24}$ Pero resulta que era aborígenes! Ellos sólo tienen rozado una hectárea y media (...)"

A finales del siglo XX, cuando el control de las fracciones incultas y deshabitadas del espacio provincial se ejerce a través de la mediación ambiental (creación de reservas y áreas protegidas), la calificación de capuera alude al monte degradado por el trabajo agrícola y la extracción de madera. Así, en Wanda (depto. Iguazú), el cacique de la comunidad Pyahu señala: "los intruchos son unas 20 personas que se dedican a plantaciones anuales, cada uno explota ilegalmente 60 o 70 ha (...) ya tumbaron 200 ha de monte y solo quedan capuerales" (El Territorio 22/03/2003). También en el depto. San Pedro, el cacique de Alecrín se lamenta: "queda solo capuera (...) muchos blancos están entrando en la comunidad y sacando madera sin nuestro permiso (...) nosotros sacamos todo de la selva, alimentos, medicinas y los materiales para hacer nuestras chozas y artesanías, ya no es más monte, queda solo capuera, en esta comunidad está todo destruido"( El Territorio 10/08/2008).

81 Como veremos a continuación, la respuesta del Estado a los reclamos por la tierra de las comunidades guaraníes en Misiones estará acompañada de un fortalecimiento de la sedentarización y de incentivos a la producción agrícola (huertas). La inclusión de las comunidades en las estrategias ambientales de control del territorio es todavía incipiente. Aun así, los saberes puestos en juego en estas últimas estrategias se derivan de una relación abstracta con el espacio, en la que la evaluación no descansa en el habitar.

\subsection{El encuadre estatal de la territorialidad guaraní: ¿colonos versus paisanos? 25}

Con el objetivo de "volver a cultivar la tierra" se llevó a cabo recientemente una reunión con funcionarios estatales, convocada por algunos caciques guaraníes. El propósito enunciado fue que:

cada comunidad vuelva a trabajar la tierra, para eso (...) nos deben garantizar herramientas y semillas (...) Debemos volver a la tierra, cultivar (...) y necesitamos ser acompañados por agrónomos (...) ya es imposible vivir de la caza y de la pesca ( El Territorio 25 /01/2017).

Si bien, en esta reunión, el tema de la propiedad sólo fue mencionado como un requisito para el acceso a servicios públicos (electricidad y agua), al cabo de un año, la comunidad del cacique convocante obtuvo la propiedad del predio que ocupa (200 ha para 300 familias; El Territorio 02/02/2018).

La relación entre el Estado y los pueblos indígenas en la Argentina recorre distintas etapas (Gorosito 2008), que van desde la dicotomía guerra/pacificación de fines del s. XIX y comienzos del XX, hasta la inclusión de la cuestión indígena y el reconocimiento de sus territorios en la Constitución Nacional en 1994, ratificando la adhesión al Convenio 169 de la Organización Internacional del Trabajo. 

del Estado fue la creación de una reserva de 3200 ha (Tamanduá, depto. 25 de mayo), centralizando el liderazgo en un cacique general. Sin embargo, en dicha reserva "sólo se establecieron sus parientes sanguíneos o afines [del cacique general] pero no el conjunto de los linajes existentes en todo el territorio, que siguieron manteniendo sus pautas tradicionales de localización" (Gorosito 2006, p. 23). ${ }^{26}$ En esa etapa también inicia su accionar la Iglesia católica a través de la cesión de un predio de 590 ha, para que 320 guaraníes desarrollen un proyecto con el fin de "afirmar cierto dominio sobre la naturaleza y, por lo tanto, independencia con respecto a ella" (citado por Enriz 2011, p. 33). ${ }^{27}$

videncian aquí las tensiones que dominarán la relación del Estado con los guaraníes a propósito de la tierra: el otorgamiento de predios tiene como contrapartida el confinamiento en superficies que restringen la esfera silvestre y la itinerancia. Las leyes provinciales de 1987 (№ 2435) y de 1989 (№ 2727) contemplan la cesión de tierras fiscales y la titulación comunitaria.

87 Si bien existen reclamos anteriores, los conflictos por la tierra guaraní se desatan a partir de la reforma constitucional de 1994. En esa década, también se intensifica en la provincia la lucha por la tierra de los pequeños agricultores ocupantes.

La Iglesia católica se convertirá en el principal mediador en la problemática de la tierra. El obispo de la diócesis de Iguazú, a cargo de la pastoral aborigen, ${ }^{28}$ defenderá también los derechos de los ocupantes. El primer encuentro por la tierra, realizado en 1997, es organizado en forma conjunta por la pastoral aborigen, la pastoral social de la zona norte y el Movimiento Agrario de Misiones (MAM) (El Territorio 6/10/1997). Asimismo, varias ediciones del Foro de la Tierra registran la participación de organizaciones campesinas y representantes del Consejo de caciques del pueblo Mbya Guaraní (El Territorio 17/9/2005).

89 El Estado provincial interviene en el tema y, a partir de 1995, cede tierras fiscales a las comunidades (2300 ha con título de propiedad en Montecarlo, San Pedro y Paraíso, El Territorio 31/01/1995) y a la Asociación del Pueblo Guaraní (7000 ha donadas en 1997 en distintos puntos de la provincia por ley № 2704, El Territorio 05/04/2003).

Los litigios a propósito de la tierra guaraní involucran situaciones en reservas ambientales, enfrentamientos con empresas madereras y con agricultores.

91 Así, a fines de la década de 1990, en un área de expansión tabacalera, en la zona oriental de Misiones (depto. 25 de mayo), el obispado transfiere a la provincia 4000 ha en las que se encuentran asentadas 300 familias de agricultores y una comunidad guaraní, compuesta por 3 familias (Ara Poty). De acuerdo a la prensa local:

Los aborígenes viven en esas tierras desde tiempo inmemorial y los propios colonos cuentan que cuando llegaron, los guaraníes 'estaban dispersos por toda la finca'. Los nuevos pobladores los fueron arrinconando y hoy, según la primera mensura, sólo tienen 200 ha. Rosalino Benítez [cacique], 39 años explica que pidieron 500 ha a [Ministerio] Asuntos Agrarios. (...) Los colonos no piensan salir de la zona que reclama la comunidad. Alceo Schenkel afirma que 'son 200 ha para 3 familias', mientras que Benítez [cacique guaraní] dice que con 500 ha vendrán más guaraníes. Resolverá el Ministerio de Asuntos Agrarios con la mensura definitiva (El Territorio 06/09/1998). ${ }^{29}$

92 En otro caso, en la zona de Wanda, en el Alto Paraná misionero, los colonos de origen polaco y criollo solicitan al gobierno provincial que "reubique a los paisanos aunque esas 
tierras les pertenezcan [lote 3 y 5 de Gdor. Lanusse]". Los términos de la solicitud expresan:

reconocemos sus derechos de afincarse, trabajar y hacer producir la tierra, que les corresponde por herencia natural (...) [pero] no es posible la convivencia entre los colonos y los aborígenes (...) No solo no respetan la propiedad ajena sino que se constituyen en activos depredadores de nuestros recursos económicos (El Territorio 05/04/2003).

También en el Alto Paraná (Puerto Libertad, depto. Iguazú) la donación de 100 ha por parte de una empresa para la comunidad guaraní Guapoy pone en evidencia la situación de 80 familias de ocupantes, constituidas por desocupados apoyados por el municipio y la pastoral católica. El predio donado “está depredado por lo que los mbya guaraní (...) irán a vivir a un flamante rozado"( El Territorio, 15/08/2003).

En el nordeste provincial, la comunidad de Alecrín (depto. San Pedro), luego de un conflicto con una empresa maderera, consiguió el reconocimiento de sus derechos territoriales en el marco de la ley de emergencia de tierras indígenas (14.169 ha; El Territorio 07/02/2012). Aun así, a los pocos años enfrentó un segundo conflicto, esta vez con los colonos. El cacique, asesorado por la pastoral aborigen, denuncia el intento de ocupación por parte de un grupo de colonos:

sufrimos una invasión por 30 familias de colonos (...) manifestaron ser de Cruce

Caballero y otros de Kilómetro 60 que al entrar en nuestro terreno comenzaron a abrir rumbos y limpiar (...) a fin de asentarse (...) cada familia con aproximadamente 25 ha" (El Territorio 07/02/2012).

Mediante la realización de un corte de ruta y el apoyo de 28 comunidades se logró desalojar a las familias de agricultores.

En el marco del litigio por la tierra que tres comunidades guaraníes mantienen con la Universidad Nacional de la Plata (titular dominial de un predio de 6035 ha, cedido por Celulosa Argentina en 1992 y convertido en área de conservación), ${ }^{30}$ se suscitaron disputas con los colonos ubicados en las zonas de transición de la reserva natural. En el año 2008, el cacique de la aldea Yvy Pytá denunció la invasión de sus tierras, cuando en una recorrida habitual se encontró con seis hectáreas aradas, troncos de árboles talados y con el cementerio totalmente arrasado. Sin embargo: "Cuando las autoridades provinciales llegaron al lugar se encontraron con otro mbya guaraní, quien les habría impedido el ingreso diciéndoles 'yo quiero ser colono, no más mbya guaraní' " (El Territorio ,2/9/2008).

97 En diálogo con este paisano (64 años), nos refiere que: "Estoy acá [en esta aldea] desde 1999. Me separé de la comunidad y me dejaron en esta parte porque no estaban de acuerdo en hacer plantaciones". Posee cultivos de yerba ( $1 \mathrm{ha})$, realizados "con mudas que fui comprando"; "media hectárea de rama [mandioca] para mercantilización con los bolseros [acopiadores]" y "entremedio de la rama tengo sandía para mercantilización en la ruta". Ocasionalmente contrata asalariados para carpidas ("pago jornal a mis parientes para hacer ese trabajo"). Cultiva dos variedades de maíz ("el de 3 meses y el de 5 meses") y conserva las semillas. También realiza producción de huerta con semillas provistas por las agencias estatales (cebollita, repollo, zapallo y zanahoria).

Los técnicos del Estado que intervienen en estas comunidades desde de 1996, a través de programas nacionales (Prohuerta y acciones de la Secretaría de Agricultura Familiar), subrayan las dificultades que entraña incentivar la agricultura entre los guaraníes. ${ }^{31}$ En 
consonancia con lo observado por Pochettino (2007), constatan que: "Los que son agricultores son casos aislados, no es toda la comunidad".

En otras aldeas guaraníes del nordeste provincial (depto. San Pedro) observamos que los indígenas que devienen agricultores son segregados del grupo y el cacique les otorga una fracción de tierra para que utilicen como propiedad individual.

En la zona central de Misiones se conformó en el año 2012 una cooperativa de trabajo, que agrupó a cinco comunidades guaraníes con el fin de desarrollar la agricultura. Las acciones emprendidas manifiestan el esfuerzo estatal orientado a generar superficies de cultivo y proveer simientes. El técnico a cargo refiere: “En el año 2012-2013 limpiamos para los aborígenes $42 \mathrm{ha}$. Chuzamos las gomas del tractor porque ellos te dicen 'acá esta mi rozado' y tenés que disquear [arar], no importa si recién está tumbado el monte y todavía están los troncos".

101 Además del servicio de arada, las agencias técnicas aportaron a las comunidades vástagos de mandioca mejorada (con mayor tenor de almidón) y semillas de maíz, obtenidas a través de un programa de rescate de variedades criollas para alimentación animal (de acuerdo a los promotores, con "más proteína y más resistencia a la sequía"). El emprendimiento no tuvo mayor duración y continuó primando el esquema de casos aislados de indígenas agricultores, en interacción fluida con los colonos, con quienes contratan los servicios de labranza del suelo a cambio del alquiler de tierras, por ejemplo.

El estudio realizado en 2010 por la pastoral aborigen con el fin de solicitar la titularización de las tierras indígenas en Misiones, desnuda un panorama preocupante. Consigna que de las 99 comunidades existentes en la provincia, solo un $23 \%$ cuenta con títulos de propiedad. Las comunidades que tienen título, lo tienen sobre una cantidad de tierra insuficiente ("la mayoría tiene menos de 25 ha. y están conformadas por muchas familias"), de modo que "no hay reconocimiento real de los territorios". Hasta el momento de realización del estudio, el relevamiento previsto por la ley de emergencia territorial solo había sido aplicado en tres comunidades de la provincia (El Territorio 01/11/2010 y 28/11/2010).

103 Las conclusiones subrayan que las empresas madereras constituyen la principal amenaza, ya que el $45 \%$ de las tierras ocupadas por guaraníes está en poder de este sector. No se menciona como competidores a los colonos y ocupantes agrícolas, pero se identifica como problemática la situación de las veinticuatro comunidades que viven al interior de áreas protegidas o reservas ambientales.

En efecto, uno de los reclamos más importantes por la tierra indígena en Misiones es el caso del lote 8 en la reserva de biosfera Yabotí. ${ }^{32}$ El conflicto enfrentó a la empresa titular del dominio con tres comunidades, que detentaban la posesión. Fue resuelto en el año 2012, a través del Ministerio de Ecología, mediante un acuerdo alcanzado con la participación de una fundación internacional. Sobre un total de 3900 ha, 200 ha quedaron para la empresa, 3000 ha para la comunidades (la mitad en condominio temporal con la fundación durante 7 años y 500 ha en condominio a perpetuidad), y un espacio fue cedido a la Provincia para un sendero (El Territorio 16/04/2012).

105 El encuadre estatal conlleva la traducción de la territorialidad guaraní a una superficie delimitada, estimada en hectáreas. Los estándares de tamaño de la tierra indígena se establecen empíricamente y oscilan entre las 3200 ha de la reserva creada en 1968 por la administración provincial, pasando por las 590 ha del predio cedido por la Iglesia católica, 
hasta las 300 ha de tierra fiscal reservadas para la población indígena en colonia La Flor (el depto. Guaraní) por un decreto provincial de 1984.

El cuadro que presentamos a continuación resume las extensiones de los territorios guaraníes mencionadas por la prensa local.

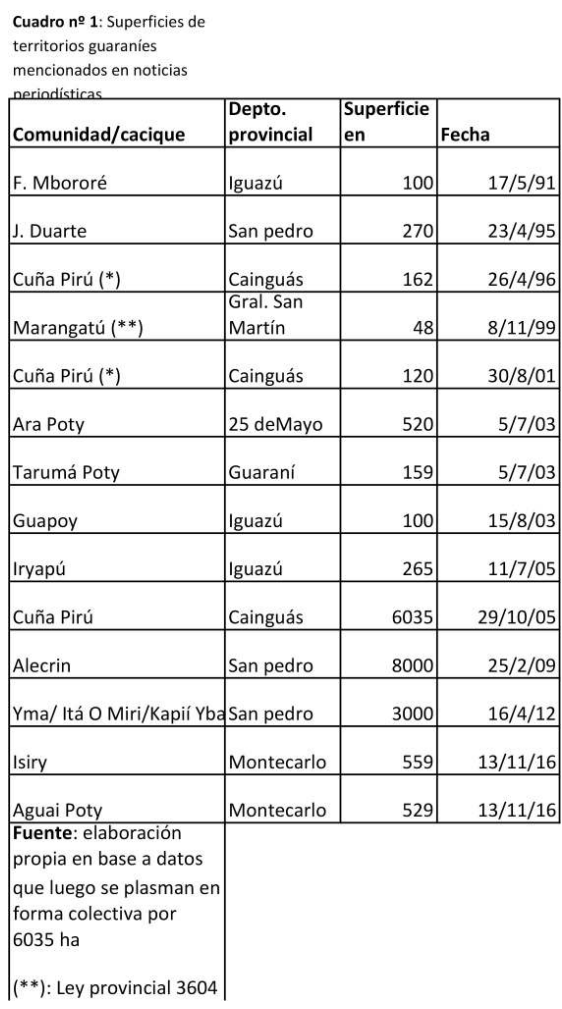

CUADRO 1: SUPERfICIES DE TERRITORIOS gUARANÍES MENCIONADOS EN NOTICIAS PERIOdíSTICAS LOCALES

Las superficies mayores corresponden a las comunidades asentadas en reservas ambientales (la de la Universidad Nacional de La Plata, en el caso de Cuña Pirú, y la de Yabotí en el caso de las tres comunidades ubicadas en el lote 8). Con respecto a la comunidad de Alecrín, la mayor extensión obedece al hecho de que está localizada en la fracción más recientemente poblada de la provincia. En los casos restantes, las superficies en juego oscilan entre 50 y 500 ha.

El enfoque relacional a partir del cual analizamos el problema de la tierra en la provincia nos lleva a concluir que la medida del territorio guaraní es fruto de la fuerza relativa de las comunidades frente a las empresas madereras y a los agricultores.

El enmarcado oficial de la territorialidad indígena se efectúa a través de mediadores que traducen el espacio habitado a la lógica estatal, solicitando la mensura de las superficies con el fin de lograr la titularización. Esta operación fija los grupos a la tierra y, de acuerdo a las afirmaciones de la pastoral aborigen de Misiones, "fortalece a la comunidad porque es un elemento oficial que indica dónde está y cuál es su territorio".

110 Las palabras de una dirigente guaraní sintetizan esta tensión: "La titularización, por más que no es suficiente la cantidad de tierra y el monte que nos queda, es una seguridad porque si no estamos con una amenaza constante" (El Territorio 01/11/2010). 


\section{Conclusiones}

111 Las conclusiones de nuestro trabajo subrayan la pertinencia de la distinción entre el habitar y el medir, en tanto modos de individuación del espacio no irreductibles, que admiten la posibilidad de traducción entre las dos modalidades.

112 El rodeo por las formas que históricamente asumió la medición del suelo nos permitió resaltar el papel de la agricultura sedentaria en la concepción de la tierra como superficie, separada de la naturaleza y sobre la que se ejerce el trabajo humano. Esta actividad acompaña la geometrización del espacio, tornándolo apto para la medición cuantitativa y para la apropiación privada.

En este sentido, la institucionalización del territorio de Misiones a partir de fines del siglo XIX ofrece un ejemplo de las dificultades que entraña para el Estado la asimilación de las prácticas de estimación asociadas a la recolección, en la que las unidades de cálculo dependen de conocimientos particularizados.

114 Indígenas y pequeños agricultores del frente pionero ponen en juego saberes del habitar, emanados del movimiento concreto, y de esta forma, tópicos. El encuadre estatal necesariamente los violenta ya que las formas generales que requiere resultan de la decantación de los recorridos del agrimensor en líneas rectas de un plano que, al despegarse de las sinuosidades concretas, se vuelven utópicas.

115 La historia de las líneas, que relata la transformación de los hilos en huellas y, luego, en trazos y conectores de un plano, es también la historia de la metamorfosis de los saberes de recorrido en una razón abstracta, que habilita el ejercicio de una dominación basada en la representación.

116 El relevamiento estatal de la territorialidad guaraní segmenta, inevitablemente, el espacio habitado. El recurso a la genealogía y a la antigüedad de la ocupación para justificar la apropiación de la tierra indígena escamotea la existencia de lazos sociales con el espacio, cuya especificidad hemos tratado de describir aquí.

117 Así, los senderos de recolección que atraviesan el monte no son conectores que van de un punto a otro sino "pasillos activos de inscripción", de acuerdo a la expresión de Ingold. La concepción del territorio depende de esos desplazamientos reales, que no pueden economizarse mediante planos $\mathrm{u}$ otros instrumentos de control a distancia.

118 La transformación del arraigo de los saberes es inherente a la modernidad pero no constituye un proceso irreversible. En efecto, los sistemas de mensura que recuperan los rumbos y las referencias de los agricultores que habitan el lugar, o los mapas de uso del ambiente utilizados en algunos de los litigios por tierras indígenas en Misiones, constituyen instrumentos que rehabilitan el conocimiento de los que recorren la tierra.

También nuestra elaboración trató de seguir el hilo de las territorialidades históricas sin tomar como punto de partida esquemas desencarnados y territorialidades cristalizadas. 


\section{BIBLIOGRAPHY}

Ambrosetti, J. (1892). Viaje a las Misiones Argentinas y Brasileras por el Alto Uruguay. La Plata: Talleres de Publicaciones del Museo.

Ambrosetti, J.(2008 [1896]). Tercer Viaje a Misiones. Buenos Aires: Albatros.

Araujo, R. (1993). La cité domestique. Stratégies familiales et imaginaire social sur un front de colonisation en Amazonie brésilienne. Tesis. Universidad de Paris X.

Azara F. de (1873). Viajes inéditos. Desde Santa Fe a la Asunción, al interior del Paraguay y Pueblos de Misiones. Buenos Aires: Imprenta y Librería de Mayo.

Baranger, D. y Schiavoni, G. (2005). Censo de Ocupantes de Tierras privadas. Estudios Regionales, 28.

Barret, R. (1926). Lo que son los yerbales paraguayos. Montevideo: Claudio García editor.

Bartolomé, L. (1990). The colonos of Apóstoles. Adaptative Strategy and Ethnicity in a PolishUkrainian Settlement in Northeast Argentina. Nueva York: AMS Press, Inc. Bartolomé, M. (2009). Parientes de la Selva. Los guaraníes mbya de la Argentina. Asunción: Centro de Estudios Antropológicos de la Universidad de Asunción.

Bertoni, M. (1927). Agenda y Mentor Agrícola. Guía del agricultor \& colono. Puerto Bertoni: Ediciones Ex Sylvis.

Bialet Massé, J. (2010 [1904]). Informe sobre el Estado de las clases obreras argentinas, Vol. 1. La Plata: Ministerio de Trabajo de la Provincia de Buenos Aires.

Bischoff, L. (2004). La tierra elegida. Posadas: Editorial Universitaria de la Universidad Nacional de Misiones.

Bourgoing A. de (1894). Viajes en el Paraguay y Misiones. Recuerdos de una expedición a los yerbales de Concepción, Cerro Corá y Sierras de Amambay, etc. Paraná: La Velocidad.

Bracco, M., Lia, V., Poggio L., Camara Hernandez, J., Gottlieb, A. (2013). Caracterización genética de razas de maíz autóctonas de Misiones, Argentina. Rev. Cienc. Tecnol. 15, (20), 52-60.

Burmeister, C. (1899). Memoria sobre el Territorio de Misiones. Buenos Aires: Peuser. Crivos, M., Martinez, M., Pochettino, L., Remorini, C., Sy, A., Teves, L. (2007). Pathways as 'signatures in landscape': toward an ethnography of mobility among the Mbya-Guarani (Northeastern Argentina). Journal of Ethnobiology and Ethnomedicine, 1-12.

Descola, Ph. (1988). La selva culta. Simbolismo y praxis en la ecología de los Achuar. Quito: Instituto Francés de Estudios Andinos y Ediciones Abyla-Yala.

Dumont, R. (1982). Terres Vivantes. Paris: Plon.

Eidt, R.(1971). Pioneer settlement in Northeast Argentina. Madison: University of Wisconsin Press.

Eloy, L. y Emperaire, L. (2011). La circulation de l'agrobiodiversité sur les fronts pionniers d'Amazonie (région de Cruzeiro do Sul, état del'Acre, Brésil). L'Espace géographique, 40, (1), 62-74.

Enriz N. (2011). Políticas públicas para familias indígenas en Misiones. Runa, XXXII, (1), 27-43. 
Felipim, A. (2001). O sistema agrícola guarani mbyá e seus cultivares de milho: um estudo de caso na aldeia guarani da Ilha do Cardoso, municipio de Cananéia, São Paulo. Tesis.Universidad de San Pablo.

Furlong, G. (1978). Misiones y sus pueblos guaraníes. Posadas: Ediciones Lumicop. Gallero, C. (Comp.) (2008). El llamado del oro verde. Memoria de inmigrantes suizos en Misiones. Buenos Aires: Araucaria Editora.

Garavaglia, J. (2011). ¿Cómo se mide la tierra? Las mensuras en el Río de la Plata, siglos XVII-XIX. En J. Garavaglia y P. Gautreau (Eds.), Mensurar la tierra, controlar el territorio. (pp. 27-61). Rosario: Prohistoria.

Gatti, L. M. (1975). Plantación, campesinado y manufactura: un caso de análisis diacrónico de la articulación de clases en el noroeste argentino. Posadas: Facultad de Humanidades y Ciencias Sociales.

Gordillo, G. (2010). Lugares de diablos. Tensiones del espacio y la memoria. Buenos Aires: Prometeo.

Gorosito, A. M. (2008). Convenios y leyes: La retórica poliíticamente correcta del Estado. Cuadernos de Antropología Social, 28, 51-65.

Gorosito, A. M. (2010). Los guaraníes de Misiones en la mirada de cronistas y antropólogos. En S. Hirsch y G. Gordillo (Comps.), Movilizaciones indígenas e identidades en disputa en la Argentina. (pp. 79-99). Buenos Aires: La Crujía.

Heck, M. (2016). Caracterización agromorfológica y de calidad nutricional de poblaciones locales de maíz de la provincia de Misiones, Argentina. Tesis. Universidad de Buenos Aires.

Ingold, T. (2000). Ancestry, generation, substance, memory, land. En T. Ingold, The Perception of Environment. (pp. 132-151). Londres and Nueva York: Routledge.

Ingold, T. (2013). Une brève histoire des lignes. Paris: Zones Sensibles.

Keller, H. (2007).Unidades de vegetación y recursos florísticos en una aldea Mbya Guaraní de Misiones, Argentina. Kurtziana, 33, (1), 175-191.

Keller, H. (2012). El origen y la decadencia de los cultivos guaraníes, un relato mítico de los avá chiripá de Misiones, Argentina. Bonplandia, 21, (1), 27-44.

Keller, H. y Romero, H. (2006). Plantas medicinales utilizadas por campesinos del área de influencia de la reserva de biósfera Yabotí (Misiones, Argentina). Bonplandia, 15, (3-4), 125-141.

Kujawska, M., Pieroni, A. (2015). Plants used as Food and Medicine by Polish Migrants in Misiones, Argentina. Ecology of Food and Nutrition, 54, 255-279.

Kula, W. (1999). Las medidas y los hombres. México: Siglo XXI.

Lefebvre, H. (1974). La production de l'espace. Paris: Eds. Anthropos.

Martinez Crovetto, R. (1968). Notas sobre la agricultura de los indios guaraníes de Misiones (República Argentina). Etnobiológica, 10, 1-11.

Martínez, M., Crivos, M., Teves, L. (2004). Owners, intruders, and intermediaries. The claim for lands within the Mbyá- Guaraní community (Valley of Cuña pirú, Misiones, Argentina). En S. Engerman y J. Metzer (Eds.) Land Rights, Ethno-Nationality, and Sovereignty in History. (pp. 347-357). Londres y Nueva York: Routledge.

Meliá, B. (2006). Escritos guaraníes como fuentes documentales de la historia paraguaya. Nuevo Mundo Mundos Nuevos [On line]. 
Michavila, L. (2017). Y ahora dice que la Universidad nos va a donar unas hectáreas. Había sido que la Universidad era la dueña. Etnografía de un conflicto de tierras en el valle del Cuña Pirú (1992-2007). Tesis. Universidad Nacional de Misiones.

Monbeig, P. (1984). Pioneiros e fazendeiros de São Paulo. San Pablo: Hucitec.

Montoya, A. de (1639). El Tesoro de la Lengua Guaraní. Madrid: Juan Sánchez.

Müller, F. (1989). Etnografía de los Guaraní del Alto Paraná. Rosario: Escuela de Artes Gráficas del Colegio Salesiano San José.

Musumeci, L (1988). O Mito da Terra Liberta. Colonização 'espontânea', campesinato e patronagem na Amazônia Oriental. San Pablo: Vertice.

Niklison, J. (2009). Vida y Trabajo en el Alto Paraná en 1914. Resistencia: Instituto de Investigaciones Geohistóricas.

Okulovich, E. (2015). La cestería Guaraní-Mbya de la Argentina: cosmología, materiales, tecnoespiritualidad e imagen en el arte actual. Posadas: Editorial Universitaria de la Universidad Nacional de Misiones.

Peyret, A. (1881). Cartas sobre Misiones. Buenos Aires: Imprenta de la Tribuna Nacional.

Pochettino, L. (2007). La dinámica en la horticultura en comunidades mbya-guaraní, Misiones, Argentina. Etnobiología, 5, 36-50.

Polanyi, K. (2007): La gran transformación. Los orígenes políticos y económicos de nuestro tiempo. Buenos Aires: Fondo de Cultura Económica.

Rengger, J. (2010). Viaje al Paraguay en los años 1818 a 1826. Asunción: Tiempo de Historia.

Rival, L (2001). Seed and Clone: The symbolic and social significance of bitter manioc cultivation. En L. Rival y N. Whitehead, Beyond the visible and the material. The americanization of society in the work of Peter Rivière. (pp.57-80). Oxford: University Press.

Rivera Rodriguez, H. y Alonso Perez, D. (2008). Léxico de pesos y medidas en el español de Nicaragua. Tesis. Universidad Nacional Autónoma de Nicaragua.

Sarreal, J. (2013). Revisiting cultivate agricultures, animal husbandry, and daily life in the Guaraní Missions. Ethnohistory, 60, (1), 101-124.

Schiavoni, G. (1995). Colonos y ocupantes. Parentesco, reciprocidad, diferenciación social en la frontera agraria de Misiones. Posadas: Editorial Universitaria de Misiones.

Schiavoni, G. (2016). El Estado y las empresas en la conformación de la estructura agraria de la Provincia de Misiones (Argentina). Boletín Americanista, LXVI, 172,1. 35-50.

Schiavoni, G. y Gallero, C. (2017). Colonización y ocupación no planificada. La mercantilización de la tierra agrícola en Misiones (1920-2000). Travesía, 19, (1), 77-106.

Sigaud, L. (1979). Os clandestinos e os Direitos. Estudo sobre trabalhadores da cana de açucar de Pernambuco. San Pablo: Livraria Duas cidades Ltda.

Souza, J. (1987). Uma introduçao ao sistema técnico-econômico guarani. Tesis. Universidad Federal de Río Grande del Sur.

Strathern, M. (2014). Sem natureza, sem cultura: o caso hagen. En M. Strathern, O efeito etnográfico e outros ensaios. (pp. 23-75). San Pablo: Cosac Naify.

Thomas, K. (1985). Dans le jardin de la nature. Mayenne: Gallimard. 
Vizolli I. y Mendes A. (2016). Braça, cuadro e tarefa: un modo de efetuar medida de terras.Vidya, $36,(1), 69-7$.

Weber, F. (2002). Práticas econômicas e formas ordinárias de cálculo. Mana, 8, (2),151-182.

Woortmann, E. (1995). Herdeiros, Parentes e Compadres. Colonos do Sul e Sitiantes do Nordeste. San Pablo-Brasilia: Hucitec.

Yssouribehere, P. (1904). Investigación agrícola en el territorio de Misiones. Anales del Ministerio de Agricultura, 1, (9). Buenos Aires: Compañía Sud-Americana de Billetes de Banco.

Fuentes:

Duplicado de Mensura № 12, 1891, Agr. Queirel, Dirección de Catastro de la Provincia de Misiones.

Duplicado de Mensura № 112, 1926, Agr. Varela, Dirección de Catastro de la Provincia de Misiones.

Diario El Territorio (Misiones)

\section{NOTES}

1. Se hace referencia a la Ley Nacional № 26160 (de 2006), que establece la suspensión de la ejecución de sentencias de desalojo de tierras ocupadas por poblaciones tradicionales, previendo el relevamiento territorial de las comunidades indígenas.

2. Entre los guaraníes de Misiones, los mbya constituyen la etnía mayoritaria. Aun así, residen en los asentamientos miembros que se reconocen como chiripá y paí Tavyterá. A fines de la década de 1970 se impuso la denominación mbya para todos los indígenas y los núcleos chiripá quedaron subsumidos. (Gorosito 2010; Bartolomé 2009).

3. Lefebvre (1974) identifica la producción del espacio como una dimensión estratégica del capitalismo, estableciendo como forma dominante el espacio abstracto, cuantitativo, geométrico y matemático, fruto de la labor de especialistas. Las formas subalternas (espacio vivido y espacio percibido) se debaten entre los intentos de codificación y homogeneización del espacio abstracto.

4. En las primeras décadas del siglo $\mathrm{XX}$, un colono suizo relata sus vínculos con el nuevo ambiente en los siguiente términos: “[el agrimensor] me proporcionó dos peones, indios guaraníes (...) Estos peones me enseñaron cómo había que ponerle el cuerpo a la selva virgen (...) Con la hoz cortaban a ras de suelo los arbustos del sotobosque y las largas tacuaras y con el machete se hacía la limpieza. Luego cortaban parcialmente los troncos jóvenes a alrededor de un metro de altura del suelo y los doblaban con ayuda de un árbol gigante de la selva, que al cortarlo con tal habilidad terminaba arrastrando y tumbando al suelo con ellos una cantidad de árboles pequeños" (en Gallero 2008, p.30). Esta técnica de desmonte es la entalladura, practicada por las poblaciones indígenas de la región amazónica (Descola 1988).

5. En griego, hyle es materia y morfe forma. Alude a un hacer que impone una forma (cuya imagen está en la mente) sobre una materia inerte. En este caso, la utilizamos para enfatizar el hecho de que el diseño del espacio antecede al poblamiento.

6. La modernidad borra el carácter concreto de las líneas, convirtiéndolas en conectores. Así, las cuerdas con las que se mensuraba inicialmente la tierra, pasan a ser las líneas geométricas del plano y esta operación supone desentenderse de la linealidad inherente al espacio de dos dimensiones en el que se ubicarán las figuras de cálculo (Ingold 2013, p. 206).

7. Queirel hace referencia aquí al “alqueire paulista”, equivalente a 2,4 ha. 
8. Señala el autor: "La medida empleada para este cómputo estadístico, no deja de ser curiosa, pues ahí no se trata de varas, cuadras cuadradas, área o hectáreas, sino de liños -medida lineal de cien varas" (Bourgoing 1894, p. 22).

9. En el estado de Sergipe (Brasil), Woortmann (1995, p. 234) menciona un testimonio del año 1856, en el que se emplea la tarefa como unidad para medir superficies cultivadas con algodón, arroz y mandioca.

10. En los ingenios azucareros del noroeste argentino, en la primera mitad del siglo XX, la tarea es mencionada como unidad de contabilización del trabajo indígena (Bialet Massé 2010; Gordillo 2010). No está operacionalizada en términos de superficie sino en cantidad de surcos de caña a plantar; va asociada a la práctica de tarjar, o sea, el registro de una cuota mínima de trabajo diario. En 1940, Gatti (1975) refiere una tarea que consiste en la plantación de 11 surcos, con 500 cañas cada uno.

11. Sin embargo, las equivalencias entre tierra y trabajo no son fijas y se ajustan a las transformaciones; así, Dumont (1982), recorriendo una plantación de caña de Pernambuco, en 1959, registra una conta de $400 \mathrm{~m} 2$, empleada para contabilizar el trabajo de un día de carpida en la plantación.

12. Equivalente a $4356 \mathrm{~m} 2$, ya que se trata de 4 cuadros de 15 brazas de lado (en vez de las 10 brazas del estado de Pernambuco).

13. En la reducción de Mártires del Japón (entre Santa María la Mayor y Concepción, en el territorio de la actual Misiones) encuentra 13.000 árboles de yerba plantados. En Paraguay, en el pueblo de San Cosme, 25.000 árboles de yerba plantados y en San Ignacio Guazú, 4000 árboles de yerba plantados en huerta pegada al pueblo (también un yerbal silvestre como en el pueblo de Corpus, en Misiones).

14. El tarefero, denominación ya mencionada por Ambrosetti en 1892, es definido por Bertoni (1927) como: "Hombre que trabaja por tarea o a condición de un mínimum de trabajo; como en el corte de Yerba Mate (del 1 marzo al 30 julio/ sept) o en recoger algodón. Del portugués tarefa-tarea (y no de tarifa)" (pp. 416-417). Está obligado a permanecer en el campamento durante toda la época de corte y debe entregar un mínimo de 6 arrobas diarias de yerba tostada (aproximadamente $70 \mathrm{~kg}$ ).

15. Ambrosetti (1892) afirma que cada tarefero entrega entre 14 y 16 arrobas por día. Barret (1926) menciona la exigencia de 8 arrobas diarias, de parte de la Industrial Paraguaya y de la Matte Larangeira. Peyret (1881) señala la exigencia de 5 arrobas diarias, poniendo de manifiesto el rendimiento desigual de los árboles (cada árbol de yerba rinde entre 1,5 y 8 arrobas).

16. Garavaglia (2011) especifica que: "Las cuadras lineales poseen generalmente 150 varas y en cuanto a las cuadras cuadradas, resultan normalmente de 150 X 150 varas, es decir 1,6874 ha" (p. 29).

17. Sobre el yerbal de San Ignacio Miní, el jesuita Nussdorfer escribe en 1747: "Como no hay que esperar mucho fruto del yerbal cercano, encargo se aumente y ensanche el que está en los montes, aunque más distante, por ser aquella tierra más propia y en donde la yerba crece mucho mejor que aquí en la cercanía del pueblo" (Furlong 1978, p. 418).

18. El naturalista suizo Bertoni subrayó el carácter hortense del cultivo de yerba, defendiendo la superioridad de la plantación pequeña, en la que la base del cálculo es la planta. Las empresas de mayor escala, obligadas a evitar las complicaciones de la policultura, cultivan una sola variedad (Ilex paraguriensis) y "actuando en terrenos de cierto costo deben hacer sus cálculos con relación a la superficie” (Bertoni 1927, p. 489).

19. "Capuera es un terreno que ha sido rozado, plantado y después abandonado, que la vegetación ha vuelto a cubrir" (Ambrosetti 1892, p. 100). 
20. Claros abiertos en el el monte para cultivo; en Montoya (1639, p. 98) el término mencionado es coiba, que alude al ramaje que queda en la chacra después del desmonte.

21. Traduce la palabra guaraní cogue que alude a plantación como 'sido pradera', señalando que “ antes de que se importara el hacha de hierro europea, solían conformarse realizando plantaciones después de quemar la vegetación herbosa en la pradera" (Müller 1989, p. 37).

22. El maíz originario de los guaraníes es el maíz blando, de ciclo corto (3 meses), conocido en Brasil como ‘saboró' (o milho verdadero, Felipim 2001). Los estudios botánicos basados en muestras provenientes de aldeas guaraníes de Misiones identifican 15 razas nativas de maíz (Bracco et al. 2013) entre las que incluyen maíces harinosos, córneo harinosos y reventadores. Otra investigación sobre maíces nativos en la provincia (Heck 2016), que incorpora además algunos materiales de pequeños productores, constata que la selección realizada por las comunidades guaraníes se orienta a la obtención de variedades harinosas para consumo humano, mientras que la llevada a cabo por pequeños productores está compuesta de maíces duros y dentados, destinados a la alimentación animal.

23. Los materiales para la confección de cestería (takuarembó, guembé, takuapí) no se cultivan. Son recolectados en el monte bajo, en la capuera, y en el monte alto. En este último ambiente, la obtención de las raíces de güembé, que cuelgan de los grandes árboles (8 a 10 metros) requiere pedir permiso al dueño o protector, una hormiga de gran tamaño denominada tarakuchi (Okulovich 2015, pp. 96-97).

24. Las capueras también toman el nombre de las especies dominantes: chircal o chilcal, con dominancia de "chilca" (Baccharis sp.). Los capuerones son capueras que se parecen al monte pero que difieren de este por la presencia de plantas arbustivas y subarbustivas en el estrato bajo.

25. La denominación paisano representa la extensión máxima de los términos de autorreconocimiento y alude a la etnia (significa compoblano o cheretarã). La población blanca en contacto con grupos guaraníes los designa con ese término.

26. El cacique ejerce la titularidad de la posesión y administra el uso de la tierra, asignando fracciones para los rozados de cada familia.

27. En 1991 se pide la expropiación de este predio que fuera donado por la Iglesia pero sobre el que pesan reclamos de una sucesión. Se argumenta en base a la ley provincial № 2435 (de 1987) y considerando el trabajo realizado: "se ha conformado un centro de producción, con aserradero propio, criaderos, chacras con cultivos anuales y perennes" (El Territorio 08/11/1991).

28. El Equipo de la Pastoral Aborigen de Misiones (EMIPA) se conformó en 1995. Además de la Iglesia católica, articula a la Iglesia evangélica del Río de la Plata, a grupos ecologistas y a la Universidad Nacional de Misiones.

29. Este pleito se zanjará a favor de la comunidad Ara Poty, que obtendrá el título de propiedad de 520 ha (El Territorio 05/07/2003).

30. La Universidad propuso la cesión de 700 ha ( 233 ha para cada comunidad) pero la oferta fue rechazada por considerar insuficiente dicha extensión para las prácticas de caza, pesca y recolección. Considerando estas actividades se reclamó la totalidad de la superficie de la reserva (Michavila 2017; Martínez et al. 2004).

31. Los obstáculos mencionados aluden a la falta de limpieza de las plantaciones ("dejaron encapuerar el maíz y después cosecharon rastrojos") y a la dificultad de adopción de las figuras rectilíneas de la naturaleza cultivada ("no hacen canteros rectos y largos. Hacen una huerta redonda y tiran ahí las semillas").

32. Creada en 1993, por una ley provincial en la zona oriental de Misiones, la reserva tiene una superficie de 253.773 ha, con 119 lotes, en su gran mayoría propiedades privadas. 


\section{ABSTRACTS}

This article analyses the interactions with respect to the land of indigenous people, colonists and landless peasants in the province of Misiones (northeastern Argentina). At the end of the 19th century, public and private extensions are measured in order to carry out plans of colonization. Indigenous groups and peasants who do not have access to the planned settlement develop alternative modes of appropriation of the environment, which we characterize here based on productive activities. We emphasize the existence of a close connection between State control and measurement of continuous surfaces for commercial agriculture. In this context, the Guarani territoriality is hard to fit within official actions. We offer a description that can historically fix the linkages and knowledge related to the land, based on the distinction between a dwelling perpective and the geometric measurement, as abstract form of control of the space.

INDEX

Palabras claves: Medida, Agricultura, Tierra, Indígena, Saberes.

Keywords: Mesurement, Agriculture, Land, Indigenous, Knowledge.

\section{AUTHOR}

\section{GABRIELA SCHIAVONI}

Consejo Nacional de Investigaciones Científicas y Técnicas - Universidad Nacional de Misiones. Argentina

Correo electrónico: gacha@arnet.com.ar 